\title{
Sustainable Development Planning of Wetlands in Kuala Trengganu District Using Satellite Imagery
}

\author{
Kamaruzaman Jusoff (Corresponding author) \\ Tropical Forest Airborne Observatory (TropAIR), Faculty of forestry \\ Universiti Putra Malaysia Serdang 43400, Selangor, MALAYSIA \\ Tel: 60-3-8946-7176 E-mail: kjusoff@yahoo.com \\ Kasawani Ibrahim \\ Faculty of Science and Technology, Universiti Malaysia Terengganu \\ UMT 21030 KualaTerengganu, Terengganu, MALAYSIA \\ Tel:60-13-938-8840 E-mail: kasawani@umt.edu.my
}

\begin{abstract}
Wetland cover mapping is very important in the sustainable planning, identifying its areal extent and the rate of change over time. This study aims to map the areal extent and its rate of change in Kuala Terengganu district for its future sustainable develoment. Three Landsat ${ }^{\mathrm{TM}}$ images, which dated on $15^{\text {th }}$ October $1998,14^{\text {th }}$ July 2002 and $15^{\text {th }}$ August 2005 were used in digital image processing by using a RGB band combination of 4, 5, and 2. The overall classification accuracies for the 1998, 2002 and 2005 images were 74.55, 82.42 and 90.91 percent, respectively. The United State Geology Survey (USGS) Classification Scheme was used to determine the wetland and the images were independently classified and total areas of wetland cover were compared between different dates of imageries. Surprisingly, there was an unexpected significant increase (from 102.35 to $381.35 \mathrm{ha}$ ) in the areal extent of wetlands in a seven year period of 1998 to 2005 with a rate of change of $0.84 \%$ increase per year. This study implies that the integration of remote sensing and Geographical Information System (GIS) may provide a useful tool for temporal studies in wetland cover and its rate of change in Kuala Trengganu district.
\end{abstract}

Keywords: Wetland, Remote sensing, Rate of change, Setiu

\section{Introduction}

Biodiversity can be defined as full range of variety and variability within and among living organisms and the ecological complexes in which they occur, and encompass ecosystem, species diversity, and genetic diversity. It is predicted that our country has a high biodiversity, as Malaysia lies in the tropics, where the climate is very suitable for a high number of species in the world that mostly inhabitants in the ecosystems of our country. Furthermore, Malaysia is also listed as one of the biodiversity hotspots in the world. Malaysia has been endowed with vast amount of natural resources including luxuriant wetland forest, which is one of the most diverse and complex ecosystems of the world. These natural resources have been identified to provide habitats for many species and providing important regional impacts, such as hydrological, biological and ecological roles in the ecosystem. Therefore, it is our responsibility to manage the wetlands well, as well as conserving them for the future.

Malaysia has a total of 96 wetlands sites approximately covered 0.34 million ha of peat swamp which was reduced almost half from 0.67 million ha in 1981 (Abdur-Rouf et al., 2007). Malaysia needs to conserve these important ecosystems for addressing flood problems, mitigating el-nino effects, estimating national water budgets and conserving biodiversity. In example, Table 1 showed the richness and diversity Malaysia aquatic ecosystem.

\section{$<<$ Table 1: Aquatic ecosystems in Malaysia $>>$}

Mapping wetland vegetation over larger regions has commonly been done using digital imagery obtained from satellites, and may be referred to as land cover mapping. Wetland cover mapping is actually providing critical information about the distributions of the species and vegetation types and "human land uses" surrounding it, thus, possible for biodiversity conservation planning, as the wetland cover classifications may link to a particular species composition and habitat types. In this case, wetland cover maps produced may provide the baseline measurements that allow the study of changes in a particular land cover over time and further discover the impacts of such changes on the biodiversity. Maps arranged according to their dates may reveal the patterns (Mitchell, 1999) and help the interpreters to infer the 
relationship (Turner et al., 1994) between the maps studied. Meanwhile, statistics in table forms summarize the findings to specifically display the increment and reduction of total areas that changed over time.

In addition, most maps used by the ecologists are land cover maps (Burel and Baudry, 2003), created from the analysis of the satellite imageries, together with aerial photographs, and through field observations that has been done by the scientists from remote sensing fields. Often, landscape ecologists use the final products of GIS processing or the interpretation of spectral data to conduct their study, as many of them are not technically proficient in all the intricacies on spatial extents that are much larger than those traditionally studied in ecology (Turner et al., 2001). Therefore, the objectives of this study are two-folds, namely (i) to map the wetland cover of Kuala Terengganu district and to determine its rate of change between 1998 and 2005, and (ii) to produce final wetland cover maps of Kuala Terengganu for each year of study

\section{Method}

The selected area of study was Kuala Terengganu district of Terengganu state, as shown in Fig.1. Kuala Terengganu is located between latitudes of $5^{\circ} 27^{\prime} 58.31^{\prime \prime} \mathrm{N}$ and $5^{\circ} 11^{\prime} 42.36^{\prime \prime} \mathrm{N}$ and longitude of $102^{\circ} 57^{\prime} 06.10^{\prime \prime} \mathrm{E}$ and $103^{\circ} 13^{\prime}$ $18.69^{\prime \prime}$ E. The capital city of Terengganu state is located in this district. The total study area is approximately 60,528 ha, which covers 4.67 percent of the Terengganu district. Three sheets of 1:50,000 scaled topography maps were used as a reference to conduct the ground truthing process. Two softwares were used in this study. Erdas Imagine 8.7 was used in the digital image processing, while ArcView 3.2 was used for the GIS analysis.

Landsat $^{\mathrm{TM}}$ was acquired from scene 126/56 (path/row), with spatial resolution of $30 \mathrm{~m}$. Images were obtained from Malaysian Center for Remote Sensing (MACRES). These images were taken on $15^{\text {th }}$ October 1998, $14^{\text {th }}$ July 2002 and $15^{\text {th }}$ August 2005. The raw images of the study areas were shown in Fig.2 by using the band combination of RGB 4, 5 , 2 .

\section{$<<$ Fig.1 Location of the study area $>>$}

\section{$<<$ Fig. 2 Raw image of Kuala Terengganu August 15, 2005>>}

Multi-dates images of Kuala Terengganu district were used to initiate this task, which involved images of 1998, 2002 and 2005. A uniform interval was expected in order to determine the land cover changes rate, but unfortunately, a uniform three or four year's intervals are not available in the archive. The seven bands of each image were layer stacked to merge them together, before producing a single image. Geometric correction process was done based on the Ground Control Points (GCP) taken during the ground truthing. A total of 50 GCPs were registered for each image; they were resampled to produce the corrected imaged. All corrected images were justified based on Root Mean Square Error (RMS Error) of less than half a pixel (Lillesand et al., 2004) by using the First Polynomial Order. The images used Rectified Skew Ortomorphic (RSO) Projection with Spheroid of Modified Everest and Kertau 1948 as the Datum. In unsupervised classification process, Iterative Self Organizing Data Analysis Technique (ISODATA) was applied to the 100 classes of unknown land covers with 30 iterations. This process is then followed by redefining the criteria for each class and classifying them again before producing the last output images of the unsupervised classification process. Wetland class was identified roughly based on the analyst's prior knowledge and from analyzing the topographical maps.

During the ground truthings, the actual wetland cover class involved was checked and identified. Global Positioning System (GPS) Garmin GPS 12 with accuracy 15m RMS was used to acquire the exact coordinates of study areas (GCP), while photographs of the wetland cover class was captured together with their details recorded. The images were then classified into wetland cover types. The analysis was done using data collected during the ground truthings with the aid of topographic maps to produce the output images of supervised classification. Next, they were filtered through the Statistical Filtering by using $7 \times 7$ modes. Mean Filter was applied for all these output images before recoding them according to the wetland class, in order to measure the areal extent of the wetland rate of change per the years studied. The output images for supervised classification process were assessed to determine the classification accuracy. Stratified Random Sampling was applied to each supervised classification images, where 30 random reference pixels were taken into account. The accuracy report was generated later that comprised the summary statistics of overall agreement percentage, together with user's and producer's accuracy. All the output images from the supervised classification were used in the GIS Analysis to determine the changes occurred amongst the temporal years under study. Each image was independently classified and registered before undergone the post-classification comparison. The rate of change was determined after calculating the total areas of wetland cover class. The changes in distribution of wetlands were shown in the generated wetland cover maps.

\section{Results and discussions}

Unsupervised classification was done to assist the ground truthing. Besides the wetland there were eleven other classes of land cover with uncertainties of the actual locations predicted during this process. The eleven classes are barren land, cloud, cloud shadow, forest land, oil palm, orchard, paddy, rubber, urban or built-up land, and water. They were nine 
classes categorized including the wetlands which were confirmed using ground verifications. Land cover classes for supervised classification images include the cloud and cloud shadow, which appeared in the images. Fig. 3 shows the images that have undergone the supervised classification that was further subset to highlight only the study area, which is the Kuala Terengganu district. A summary of the total area for each land cover classes, especially the wetlands in every image were demonstrated in Table 2 according to their respective year of study to measure the rate of change for the three temporal years.

\section{$<<$ Fig. 3 Supervised classification image of K. Terengganu for 1998, 2002 and 2005>> \\ $<<$ Table 2: Total areas of land cover and land use for 1998, 2002 and 2005 image of $\mathrm{K}$. Terengganu $>>$}

Based on the results, all Root Mean Square Error (RMS Error) obtained are less than a pixel. In this study, the spatial resolution of each data used is $30 \mathrm{~m}$, which represented by a pixel. Therefore, the errors obtained should not be more than the image resolution, which means not more than $30 \mathrm{~m}$. Furthermore, for the change detection analysis, a requirement of accurate spatial registration during geometric correction could bring an effective result for each dates of imagery. Ideally, the RMS Error should not be more than half a pixel.

\subsection{Accuracy assessment}

In accuracy assessment, a total of 330 stratified random sampling points was used to determine the accuracy for each output images of the supervised classification. The overall classification accuracy obtained for 2005 image is the best, which is $90.91 \%$. The overall accuracy for 1998 and 2002 images can be considered as moderate, where the accuracies are $74.55 \%$ and $82.42 \%$, respectively.

\subsection{Geographical Information System (GIS) analysis}

Arc View 3.2 software was used in the GIS analysis to enable determination of the total changes of areas for each class, when the images were compared. The arrangement of the classes was done by putting the priority, based on the highest to lowest increment of total area that changed from 1998 to 2005, and further followed by the highest to lowest changes reduction of the total area. For wetland class, distribution of the particular land cover is shown in Figure 4. In 1998, the total area is $2.18 \%$ or 102.348 ha. The value decreased slightly in 2002 to be $2.15 \%$ or 100.683 ha. Surprisingly, the value of total area of this class expanded in 2005 to be $8.13 \%$ or 381.348 ha.

\section{$<<$ Fig. 4 Wetland covers type maps of K. Terengganu for 1998, 2002 and 2005>>}

The total area of wetlands has increased to $5.95 \%$ or 279 ha from 1998 to 2005 . In 2005 , the total area for wetlands was observed to be higher compared to the earlier years of study. This might be due to the inexperienced analyst, where the spectral reflectance of other land use cover such as rice paddy areas was misinterpreted as wetlands. Meanwhile, in 2005, the areas of Wetland class were observed in more detailed, as the ground truthings enable determination of the exact wetland cover involved in the area. Furthermore, seasonal peat swamps are included in this class, where this class is influenced by the water table to be mistakenly interpreted as the rice paddies class. Basically, the weakness in interpretation of this class is due to the lack of knowledge of the study area in the earlier years of study.

With the aid of ground truthing and further analysis of the ancillary data, it is observed that the wetlands of K. Terengganu district were found in Kampung Mengabang Panjang in Batu Rakit, Kuala Nerus subdistrict, Gong Badak industrial areas and Gelugur Raja, mainly associated with wetland floras of sea hibiscus (Hibiscus tiliaceus), nipah palm (Nypa fruticans) and mangrove fern (Acrostichum aureum). Forested wetland is dominant in Kuala Terengganu and most of the mangrove trees observed were Avicennia, Sonneratia, Rhizophora and Melaleuca genera.

Wetland areas have their own international importance, as they provide the natural protection to the coastal areas from the strong storms, as well as the sand erosion. They have a high biological diversity and traditionally utilized for food resources, firewood, charcoal and timber (Yousif et al., 1999). Wetland has been recognized to be the breeding areas and refuges for many marine species, including prawns. Mangrove is also capable in preserving water quality and reducing the water pollutions by filtering suspended materials and assimilating dissolved nutrients. Since wetland areas protect the human and the human settlements, they are eventually have become our responsibility to take care of them, so that people do not have to worry too much about the disasters that might occur if these areas are eliminated.

\section{Conclusion}

Landsat ${ }^{\mathrm{TM}}$ images are capable of identifying the Kuala Trengganu District wetland cover class and its rate of change for its future sustainable development planning and management. Overall classification accuracy obtained for 1998, 2002 and 2005 images are $74.55 \%, 82.42 \%$ and $90.91 \%$, according to their respective years of study. These values show a moderate accuracy for 1998 and 2002 images, meanwhile, 2005 image has the best accuracy assessment. Wetlands sometimes confuse with rice paddies class. Generally, the integration between remote sensing and GIS in this study has proved its ability to determine the wetland cover classes, as well as the other land cover changes between the study periods. It is recommended that the satellite imageries with higher spectral and spatial resolutions be used for future wetland cover map production in order to improve the mapping accuracy. 


\section{References}

Abdur-Rouf, A.J.M., Noor-Azhar, M.S., Mohd-Lokman, H. and Rosnan, Y. (2007). A conceptual framework for classifying and assessing Malaysia wetlands. In: K., Kobayashi, and A, Maisarah, (Eds), Proceeding of International Seminar on Wetlands and Sustainability, $4^{\text {th }}-6^{\text {th }}$ September, 2007, Puteri Pacific Hotel, Johor Bharu, Johor, pp $281-292$.

Burel, F. and Baudry, J. (2003). Landscape Ecology: Concepts, Methods and Applications. New Hampshire: Science Publishers, Inc.

Mitchell, A. (1999). The ESRI ® Guide to GIS Analysis. Volume 1: Geographic Patterns and Relationships. California: Environmental Systems Research Institute, Inc.

Turner II, B.L. and Meyer, W.B. (1994). Global land-use and land-cover change: an overview. In W.B. Meyer and B.L. Turner II (eds). Changes in Land Use and Land Cover: a Global Perspective. Cambridge: Cambridge University Press. pp. 3-10.

Turner, M.G., Gardner, R.H. and O’Neill, R.V. (2001). Landscape ecology in theory and practice: Pattern and Process. United States of America: Springer-Verlag New York, Inc.

Yousif, A., Hussin, M., Zuhair, M. and Weir, M. (1999). Monitoring Mangrove Forests using Remote Sensing and GIS. Poster Session 5.

Yusoff, F.M. and Gopinath, N. (1995). The status of inland fisheries in Malaysia. In: T. Peter, M. Morris (Eds), Indo-pacific Fishery Commission, FAO Report No. 512 Supplement, pp 225-239.

Table 1. Aquatic ecosystems in Malaysia

\begin{tabular}{ll}
\hline Habitat Peninsular Malaysia & Area $\left(\mathbf{k m}^{\mathbf{2}}\right)$ \\
\hline Rivers including floods plains & 9,111 \\
Peat swamps & 4,850 \\
Reservoirs & 1,600 \\
Mining pools & 164 \\
\hline East Malaysia & \\
\hline Rivers including flood plains & 8,487 \\
Peat swamps & 15,150 \\
Reservoirs & 22 \\
\hline Total & $\mathbf{3 9 , 3 8 4}$ \\
\hline
\end{tabular}

Source: Yusoff and Gopinath, 1995

Table 2. Total areas of land cover and land use for 1998, 2002 and 2005 image of K. Terengganu

\begin{tabular}{|c|c|c|c|c|c|c|}
\hline \multirow{2}{*}{ Classes } & \multicolumn{2}{|l|}{1998} & \multicolumn{2}{|l|}{2002} & \multicolumn{2}{|l|}{2005} \\
\hline & $\mathrm{Ha}$ & $\%$ & ha & $\%$ & ha & $\%$ \\
\hline Barren Land & 92.22 & 1.97 & 39.46 & 0.84 & 63.135 & 1.35 \\
\hline Cloud & 204.96 & 4.37 & 140.87 & 3.00 & 66.321 & 1.41 \\
\hline Cloud Shadow & 185.86 & 3.96 & 76.04 & 1.62 & 9.639 & 0.21 \\
\hline Forest Land & 264.40 & 5.64 & 77.39 & 1.65 & 49.437 & 1.05 \\
\hline Oil Palm & 58.46 & 1.25 & 238.19 & 5.08 & 382.329 & 8.15 \\
\hline Orchard & 1612.14 & 34.39 & 1841.40 & 39.26 & 1274.049 & 27.16 \\
\hline Paddy & 405.06 & 8.64 & 362.27 & 7.72 & 772.182 & 16.46 \\
\hline Rubber & 534.94 & 11.41 & 478.84 & 10.21 & 1017.756 & 21.70 \\
\hline $\begin{array}{l}\text { Urban or Built-up } \\
\text { Land }\end{array}$ & 1109.52 & 23.67 & 1214.33 & 25.89 & 500.328 & 10.67 \\
\hline Water & 118.19 & 2.52 & 121.14 & 2.58 & 174.132 & 3.71 \\
\hline Wetlands & 102.34 & 2.18 & 100.68 & 2.15 & 381.348 & 8.13 \\
\hline Total & 4688.13 & 100 & 4690.65 & 100 & 4690.65 & 100 \\
\hline
\end{tabular}




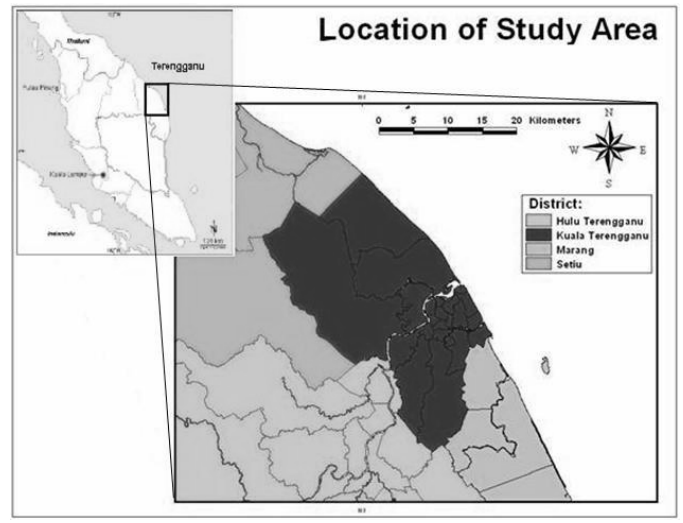

Figure 1. Location of the study area

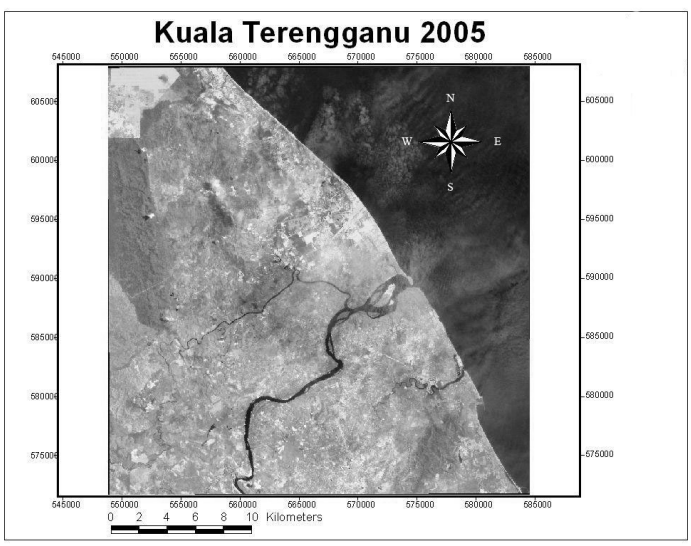

Figure 2. Raw image of Kuala Terengganu August 15, 2005

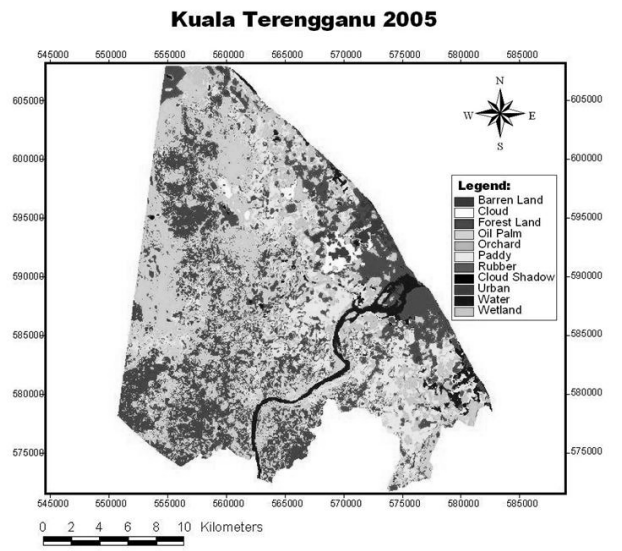

Figure 3. Supervised classification image of K. Terengganu for 1998, 2002 and 2005 

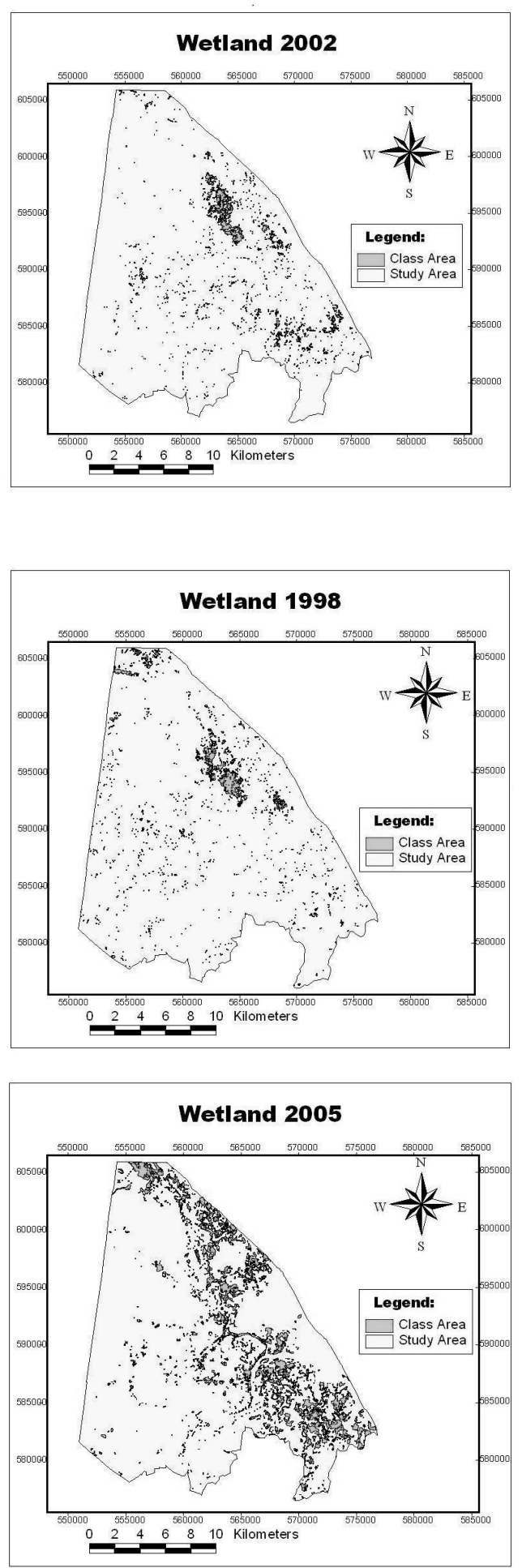

Figure 4. Wetland cover type maps of K. Terengganu for 1998, 2002 and 2005 